\title{
A prática fotográfica e as questões étnico-raciais: entre poética, documento e política ${ }^{1}$
}

Elson de Assis RABELO²

\begin{abstract}
Resumo:
Neste trabalho, discuto sobre fotografias e trajetórias de fotógrafos negros contemporâneos na Bahia, como inserção em diferentes circuitos sociais das imagens, como afirmação das práticas culturais negras e como enfrentamento das desigualdades sociais baseadas em cor. Também abordo o papel das práticas de arquivamento no diálogo com as memórias e com as demandas atuais por olhares negros nas narrativas e nos espaços expositivos.
\end{abstract}

Palavras-chave: história; fotógrafos negros; fotografia baiana.

\section{Photographic practice and racial questions: among poetics, document and politics}

\begin{abstract}
:
In this work, I talk about photography and trajectories of Black contemporary photographers in the Brazilian State of Bahia, as a kind of presence in the different social circuits of images, as affirmation of Black cultural practices and also as fight against the social inequalities based on race and color skin. I also discuss on the role of the practices of archiving in dialogue with memories and the contemporary needs for Black looks in the narratives and exhibition spaces.
\end{abstract}

Keywords: history; Black photographers; photography from Bahia.

\section{La práctica fotográfica y las cuestiones étnico-raciales: entre poética, documento y política}

\section{Resumen:}

En este texto, hago planteamientos sobre fotografias y trayectorias de fotógrafos negros contemporáneos en el Estado brasileño de Bahia, como una forma de inserción en distintos circuitos sociales de imágenes y afirmación de prácticas culturales negras y lucha en contra de desigualdades sociales basadas en raza. Igualmente, planteo consideraciones sobre el rol de las prácticas de archivamiento en diálogo con las memorias y las necesidades contemporáneas de miradas negras en las narrativas y en los espacios expositivos.

Palabras clave: historia; fotógrafos negros; fotografía de Bahia.

\footnotetext{
${ }^{1}$ Este trabalho é a versão estendida de uma apresentação no XIII Encontro Nacional de História da Mídia, ocorrido entre 18 e 20 de agosto de 2021, em Juiz de Fora, Minas Gerais, em modalidade virtual.

${ }^{2}$ Doutor em História pela Universidade Federal de Pernambuco, com Estágio Sandwich na Escuela Nacional de Antropología e Historia, na Cidade do México. Professor Adjunto do Colegiado de Artes Visuais e do Curso de Licenciatura em História - Convênio PRONERA, da Universidade Federal do Vale do São Francisco. Colaborador do Programa de Pós-Graduação em Artes Visuais, da Universidade Federal da Bahia. E-mail: elson_rabelo@hotmail.com.
} 


\section{Provocações para uma introdução}

Primeira inquietação: peço licença para dedicar este trabalho à memória de Januário Garcia, falecido no último 30 de junho de 2021, vítima da Covid-19. Fotógrafo ligado aos movimentos sociais negros do Brasil, Januário, ao longo de mais de 50 anos de trajetória, produziu centenas de milhares de imagens das práticas culturais e das formas de organização política locais e transnacionais dos grupos negros na diáspora, de suas marchas e festas, dos quilombos brasileiros e dos palenques dos países de colonização espanhola, das favelas e terreiros. Para ele, havia histórias e vidas por detrás e para além das imagens, na medida em que suas fotografias dialogavam com o passado, com o presente e com aquilo que foi conceituado por Luiza Bairros (1996) como as definições contemporâneas do que é ser negro no Brasil, a partir da segunda metade do século XX. Nas fotos que produziu, a partir do que ele mesmo conceituou como um olhar negro (GARCIA, 2021), Janu vive. As imagens, suportes das memórias.

Segunda inquietação: em nossos dias, estamos a passos largos no sentido da naturalização do reconhecimento eletrônico da face humana, como continuidade dos mecanismos de vigilância através das imagens. Na sociedade brasileira, os setores de monitoramento das secretarias de segurança de alguns estados, com destaque para a Bahia e o Rio de Janeiro, têm feito franco uso de câmeras instaladas em espaços públicos, das imagens que elas produzem e de seu entrecruzamento com dados individuais e com outras imagens, como fotografias, que se encontram sob poder das polícias (FALCÃO, 2021). A justificativa para tal uso seria o incremento de políticas de segurança que combateriam mais eficazmente a violência, ao rastrear e encarcerar sujeitos identificados - o que, em uma sociedade historicamente racista como a nossa, tem ocorrido com margens de equívocos e de arbitrariedades (FALCÃO, 2021). Se as democracias ocidentais tardaram a diagnosticar a ameaça desses dispositivos, os movimentos sociais organizados e os grupos subalternizados e racializados, como os imigrantes, os refugiados e a população negra habitante de grandes cidades, como no Brasil, já vêm sentindo o risco de serem tratados como objetos dessas imagens, dissolvidos em estereótipos faciais que os despersonalizam. No centro dessa discussão, as forças de segurança, empresariais ou estatais, colocam-se como produtoras de imagens, impondo-nos questões sobre o papel da imagem nos processos contemporâneos de 
racialização e de subalternização e sobre o investimento social em imagens que teriam uma economia específica de circulação e de usos (DAMASCENO; FERNANDES, 2021). As imagens, dispositivo de controle.

Diante dessas provocações, este texto se propõe a fazer um recorte de trajetórias de dois fotógrafos negros contemporâneos na Bahia, a saber: Bauer Sá e Jônatas Conceição, situando seus olhares, que tipo de imagens eles produziram, em perspectiva histórica. Do ponto de vista metodológico, indicaremos os circuitos de produção, circulação e consumo das imagens que eles produziram e a relação desse circuito com os processos de racialização e subalternização dos grupos sociais negros na Bahia, nos anos 1980 (MENESES, 2002). Indagamos como esses circuitos constituíram espaços discursivos para a imagem fotográfica feita por sujeitos negros, desdobrando-a como prática que demarcava os lugares sociais e as formas de reconhecimento por parte desses fotógrafos e como artefato material que teve diversos usos e que, com o passar dos anos, foi arquivado, segundo diferentes políticas de memória e de institucionalização (KRAUSS, 2010).

\section{"Diz em que cidade você se encaixa/Cidade Alta, Cidade Baixa"}

O trecho da música Duas Cidades, do grupo BaianaSystem, de 2016, oferece-nos uma referência espacial e social ilustrativa das trajetórias que pontuamos, neste texto. A divisão entre as duas cidades não seria exatamente geográfica, como veremos, embora histórica e materialmente a cidade de Salvador se divida entre Cidade Alta, onde reside grande parte das classes médias e altas, e Cidade Baixa, onde boa parte das periferias se localiza. Mas passemos às trajetórias.

Filho do também fotógrafo baiano Armando Sá, com quem trabalhou e aprendeu a fotografar, Bauer Luiz Sá nasceu em Salvador, em 1950. No final do decênio de 1970, Bauer trabalhava no Polo Petroquímico de Camaçari, uma instituição cujos postos de trabalho ajudaram a recompor as posições de classe de vários sujeitos negros, suscitando o surgimento de uma nova geração de classe média, com acesso à instrução, ao intercâmbio de referências político-culturais e às possibilidades de inserção no campo da produção artística (PINHO, 2010, p. 31. 92).

Bauer foi um dos fotógrafos que cedo se integrou ao Grupo de Fotógrafos da Bahia, criado em 1978, tendo feito parte do núcleo principal que organizava as ações, com Aristides 
Alves, Célia Aguiar, Isabel Gouvêa, Adenor Gondim e outros. Avançando em iniciativas que se deram ainda nos anos 1960, nas Bienais de Arte da Bahia, o Grupo se notabilizou por consolidar o espaço discursivo do sistema de arte para a fotografia baiana, na medida em que, ao longo dos anos até 1984, levou a imagem fotográfica para exposições no foyer do Teatro Castro Alves, no Museu de Arte da Bahia e no Museu da Imagem e do Som de São Paulo. As exposições chamadas de Fotobahia acabaram por dar nome ao Grupo, que promovia também oficinas para o aprendizado de técnicas fotográficas e de revelação, e atividades políticas e culturais em que se discutiam a inserção social do fotógrafo, sua profissionalização, a situação do mercado e as condições de trabalho.

No ano de 1981, o Grupo de Fotógrafos da Bahia organizou o "I Encontro Nacional de Fotógrafos", realizado junto com a exposição daquele ano dentro da programação da $33^{\mathrm{a}}$. Reunião Anual da Sociedade Brasileira para o Progresso da Ciência (SBPC), no Campus de Ondina da Universidade Federal da Bahia. Essa reunião convocava os participantes ao diálogo com os movimentos sociais, e a exposição fotográfica tinha como tema central "O homem e a sociedade", e os subtemas "A população brasileira - rural e urbana", "O negro na sociedade brasileira” e “A luta indígena” (GRUPO DE FOTÓGRAFOS DA BAHIA, 1981).

Ali, o grupo baiano se inteirou do projeto de lei do deputado catarinense Ademar Ghisi, que propunha a regulamentação da profissão do fotógrafo. Além disso, o Fotobahia se aliou aos demais grupos de fotógrafos do Brasil, como a União dos Fotógrafos de Brasília, a União dos Fotógrafos do Estado de São Paulo, a Associação Riograndense de Repórteres Fotográficos, o Sindicato de Jornalistas de Brasília, o Sindicato de Jornalistas de Porto Alegre, a Cooperativa dos Fotógrafos do Rio Grande do Norte e o Clube da Objetiva de Goiânia. Eles contestavam as limitações do projeto, reivindicavam a inclusão de categorias profissionais como os fotógrafos lambe-lambe, a isenção de taxas de importação para materiais e equipamentos fotográficos e a liberdade de expressão, num momento em que a censura do regime ditatorial ainda era vigente (UNIÃO DOS FOTÓGRAFOS DE BRASÍLIA, 1981).

Em termos de linguagem fotográfica, a fotografia documental estava sendo reinventada, prestando-se ao uso como ferramenta de denúncia social, que estava no horizonte político e criativo de fotógrafos ligados ao fotojornalismo ou recém-saídos dele em direção a projetos autorais independentes das pautas dos periódicos de notícias (SOUSA, 2004; ROUILLÉ, 2009). Para muitos fotógrafos de Fotobahia, incluindo Bauer Sá, Adenor Gondim 
e Euvaldo Macedo Filho, a imagem documental era uma linguagem importante para a produção de imagens sobre a Bahia que pudessem trazer a marca do olhar de diferentes sujeitos, a partir de elaborações nativas que destoariam da tradição dos estúdios comerciais, da imprensa e do campo dos estudos afro-brasileiros (FALCON, 2006).

Também a partir dos anos 1980, Sá produziu um tipo de fotografia que veio a destacar sua trajetória. Sua poética as aproxima das experimentações artísticas ou do que foi chamado por André Rouillé (2009) regime expressivo da fotografia. São imagens que centralizam os corpos negros, frequentemente segmentando-os, pondo em relevo o reflexo da pele no primeiro plano e com poses que sugerem performances com objetos, animais e poucas vestimentas ${ }^{3}$.

Bauer havia contribuído com imagens parecidas com essas para uma exposição chamada Tendências Estéticas Afro-baianas, que foi uma das atividades organizadas por estudantes para demarcar o espaço do Museu Afro-brasileiro (MAFRO) criado no âmbito do Centro de Estudos Afro-Orientais da UFBA, em 1974, mas só inaugurado em 1982, nas dependências da Faculdade de Medicina da Bahia, no Terreiro de Jesus. As fotos destacam os penteados feitos com cabelos crespos, em sua diversidade e possibilidades de arranjo, consolidando no espaço expositivo museal uma temática que estava na agenda dos movimentos sociais negros, em termos de afirmação criativa e política: a estética capilar. As fotos mostram cabelos trançados e rostos que não aparecem, em um diálogo vigoroso com marcadores étnicos que tinham sua espessura histórica nos modos de comportamento e de colocação do corpo e dos cabelos que enfrentaram as barreiras ocidentais da beleza e os crivos de boa aparência do mercado de trabalho.

Após adentrarem e ajudarem a constituir o espaço discursivo de um museu etnográfico, as imagens de Bauer se desdobram no tempo: da exposição ao arquivamento museológico, os usos da imagem demarcavam a presença dos corpos negros na prática fotográfica, atrás e diante das câmeras. Essas imagens se encontram, hoje, na reserva técnica da instituição, e seu lugar no ecossistema arquivístico e na política de preservação do museu sinaliza que se trata de um tipo de fotografia que adquiriu valor expositivo próprio, isto é, que sua materialidade foi arquivada a partir das únicas cópias existentes por seu estatuto de coisa autônoma, e não por atuar como objeto reprodutível que servisse de ilustração etnográfica

\footnotetext{
3 Um recorte das imagens produzidas por Bauer Sá, sejam documentais ou de caráter experimental e performático, podem ser vistas em seu website, disponível em: https://bauerssa.wixsite.com/bauersa.
} 
sobre os contextos de uso dos demais artefatos da cultura material africana ou afro-brasileira (EDWARDS, 2021; COSTA, 2008).

À altura da exposição daquelas fotos, Bauer estava com aproximadamente 32 anos de idade e era um dos poucos fotógrafos negros com participação constante e ativa no Grupo de Fotógrafos da Bahia. Ele estava ao lado de nomes como Anízio Carvalho, hoje nonagenário com mais de 50 anos de carreira na imprensa soteropolitana; e Juarez Paraíso, que era reconhecido como artista visual que transitou das poéticas modernistas para as contemporâneas, curador da Bienal da Bahia, professor da Escola de Belas Artes da UFBA e que contribuiu pontualmente com o Fotobahia. Juarez, em particular, tendo sido reconhecido como produtor de imagens transgressoras, que cruzavam a fronteira do erótico, foi também um dos principais interlocutores entre o grupo de fotógrafos, suas reivindicações profissionais, e a universidade, espaço discursivo de formação que ainda não havia se aberto à fotografia por não considerar seus processos criativos como parte dos currículos.

Mas até aqui viemos falando de linhas de vidas cujas práticas fotográficas penetraram um universo social ocupado, de maneira predominante, por pessoas socialmente marcadas como brancas, o que dá um contraponto importante, na medida em que Fotobahia chegou a congregar dezenas de fotógrafos - sendo os negros minoria -, enquanto cerca de dois terços das pessoas fotografadas, de acordo com as imagens que aparecem nos catálogos, são negras. Para entender esse interesse dos fotógrafos brancos por fotografar sujeitos negros, remontamos, decerto, ao dado demográfico de que a capital baiana possui uma maioria esmagadora de pessoas negras. Mas isso se explica também por aquilo que Osmundo Pinho (2010) nomeou como reafricanização da cultura baiana, que se operou por quatro vetores em Salvador no final do século XX: a articulação entre raça e classe, a revisão crítica do Candomblé jeje-nagô, a reconstituição do carnaval afrodescendente e a formação de uma consciência insurgente, por meio dos movimentos negros.

Para Pinho (2010), essa reafricanização interferiu na autoimagem dos sujeitos baianos, em suas práticas e políticas de representação. Essa metáfora da imagem pode ser desdobrada na concretude da imagem fotográfica, como prática social requerida pelos sujeitos negros, seja na dimensão do exercício profissional, seja na intervenção que a imagem exerce na cena pública, nas memórias familiares, na experiência perturbadora do racismo e no combate às desigualdades baseadas em raça. 
Além disso, o campo das práticas culturais tinha relações inextricáveis com as transformações sociais e econômicas, apontadas no incremento das relações capitalistas, de que era exemplo a referida consolidação do Polo Petroquímico de Camaçari, o crescimento demográfico, especialmente das populações dos bairros periféricos e a organização do Carnaval e das festas de largo sob modelos empresarizados para o turismo, o que se acentuou nos anos 1980.

Nesses cenários, a prática fotográfica produzia imagens a serem expostas nos circuitos artístico e museal, mas já tensionavam a iconosfera das imagens de corpos negros feita na perspectiva da folclorização, do turismo, ou mesmo do olhar etnográfico que marcou a fotografia na Bahia, nas décadas anteriores (OLSZEWSKI FILHA, 1989; NEGRO, 2020; SANSONE, 2012). Ficava mais explícito na imagem fotográfica que o negro, muito frequentemente tido como objeto de cultura, ou objeto de ciência, transitava para o sujeito negro, organizado coletivamente tanto em suas práticas culturais, quanto em sua luta política. A relação entre sujeito e objeto se invertia, quando esses sujeitos racializados, e tantas vezes subalternizados, passavam a criar imagens: os negros também olham, devolvem o olhar. E seu olhar é uma agência, que, por sua vez, produzia imagens como artefatos com usos sociais (MITCHELL, 2015; HURSTON, 2019).

E aqui, após acompanhar como fotógrafos negros se inseriram em um circuito de "Cidade Alta" onde eles eram minoria, abordamos outros espaços discursivos onde a imagem fotográfica é que era minoritária, pouco pensada ou vista como uma prática menor, em relação às questões sociais mais candentes. Trata-se exatamente dos movimentos negros, nos quais atuou vigorosamente Jônatas Conceição da Silva e onde ele se formou como fotógrafo autodidata, numa "Cidade Baixa", ocupada publicamente pelos sujeitos negros.

Jônatas nasceu em 1952, havia se formado em Letras e ajudou a organizar o Grupo Nêgo, no final da década de 1970. Esse grupo logo se tornou a representação baiana do Movimento Negro Unificado, cuja criação se deu em 1978, na escadaria do Teatro Municipal de São Paulo, evento ao qual Jônatas compareceu. No final dos anos 1970 e no começo dos anos 1980, Jônatas passa a compor e publicar poesia, torna-se coeditor do jornal Nêgo, do MNU baiano, trabalha com o bloco afro Ilê Aiyê, atua na imprensa e no rádio, articula-se nacionalmente com grupos de outros estados, e, especialmente, começa a fotografar as passeatas do MNU, em Salvador. Entre essas passeatas, estava a Marcha da Consciência 
Negra, realizada no mês de novembro, que havia sido criada pelo Grupo Palmares, de Porto Alegre, em memória da morte do líder quilombola Zumbi. O MNU acolheu a data e ajudou a nacionalizar a efeméride, a fim de se contrapor às comemorações oficiais da ditadura militar em torno do 13 de maio - que acenavam para o discurso da democracia racial - e destacar o protagonismo dos grupos negros, as reivindicações por direitos e os manifestos contra o racismo (GELEDÉS; CULTNE; REDE DE HISTORIADORES NEGROS, 2020).

Quando Jônatas começou a fotografar, alguns desses mesmos sujeitos presentes nas manifestações estiveram numa marcha, ocorrida na mesma reunião da SBPC, na UFBA, onde houve a exposição de Fotobahia. Na foto de autoria de Juca Martins, comentada pela irmã de Jônatas, Ana Célia Silva (2020), aparecem ela própria, Jônatas, Ismael Ivo, Gilberto Leal, Luiza Bairros, Hamilton Cardoso, Lino de Almeida e crianças empunhando cartazes pelo ensino de cultura e história afrobrasileira.

As fotos de Jônatas também indicam um olhar voltado para os sujeitos em grupo e em movimento, nos espaços públicos do Centro Histórico de Salvador, muitas vezes à noite, com luz escassa, como na primeira marcha, de $1980^{4}$. Em meio às faixas, cartazes e palanques, o fotógrafo coloca em relevo ainda militantes históricos, como Luiza Bairros, Wilson Santos, Gilberto Leal, dentre outros, que contribuíram com seu pensamento e sua atuação para dar forma às pautas negras na Bahia.

Um percurso comum das marchas era o deslocamento da Praça do Campo Grande até a Praça Municipal, passando pelo Teatro Castro Alves, mesmo espaço onde, internamente, Bauer, Anízio e Juarez expunham seus trabalhos em Fotobahia - sinalizando para o cruzamento difícil entre as Cidades Alta e Baixa, entre o cubo branco onde penetraram os fotógrafos negros e a rua, como espaço discursivo do enfrentamento e da afirmação política. Se os fotógrafos negros de Fotobahia não enfatizaram a denúncia em sua linguagem documental, as fotos de Jônatas carregam a marca da denúncia não pelo que mostram, mas pelo que sugerem dos enunciados do protesto.

Naquele momento de recomposição da imagem dos grupos negros, a fotografia de Jônatas Conceição dialogava com noções como as de quilombo e de quilombismo, que vinham sendo formuladas por Abdias Nascimento e por Beatriz Nascimento: uma forma de organização e um projeto político contra a permanência e a sofisticação da desigualdade racial

\footnotetext{
${ }^{4}$ Fotos dessas marchas podem ser vistas na exposição virtual do Zumvi Arquivo Fotográfico, com narração do fotógrafo Lázaro Roberto dos Santos, disponível em: https://www.zumvi.com.br/exposicao/tres-grandes-pautaszumvi-arquivo-afro-fotografico-salvador-bahia/.
} 
na sociedade brasileira. São imagens que se forjam no esforço de reconstrução das formas de ser negro no Brasil e na disputa por uma política, partidária e não partidária, que pressionava pelo fim do regime autoritário e por uma redemocratização que se estenderia pelos anos 1980 afora, emandando dos agentes sociais negros um conjunto de elaborações teóricas e pragmáticas - como a patrimonialização da memória do Quilombo dos Palmares, a criminalização do racismo, o combate à violência policial, dentre outras, a ocupação dos espaços de produção de conhecimento.

Sintomático dessa insurgência negra foi o debate proposto por Jônatas em 21 de agosto de 1987, ao entrevistar, no programa Afro Bahia, da Rádio Educadora, de Salvador, o jornalista Hamilton Vieira. O programa havia sido idealizado e roteirizado por Jônatas, como plataforma para entrevistas com pessoas de referências do Candomblé, da literatura, da imprensa. Ali também eram veiculadas músicas de diferentes gêneros musicais africanos e da diáspora africana, como samba, jazz, reggae, afrojazz, e eram recitados contos, poesias e trechos de romances africanos. Aqui, aproximamo-nos metodologicamente da especificidade sonora desses artefatos não para reduzir a leitura das imagens e de seu circuito à oralidade das músicas e das falas nas entrevistas, mas para enriquecer a hermenêutica do olhar a partir dos diálogos e referências que podem ter incidido sobre a constituição sempre impermanente do olhar do fotógrafo (MAUAD, 2008; SANTHIAGO, 2013).

Hamilton Vieira era jornalista e integrante do MNU, tendo se tornado um dos responsáveis por levar pautas negras para a grande imprensa, além de publicar textos nos jornais dos movimentos sociais sob o pseudônimo Estêvão dos Santos. Sua entrevista em áudio com Jônatas é marcada por um exercício de ekphrasis, isto é, de descrição crítica a respeito de imagens, especialmente aquelas que se cristalizaram sobre os grupos negros. Hamilton dizia, de forma contundente:

O que nos causa maior indignação é exatamente isso, é saber que essas pessoas, que são tão exploradas para ilustrar revistas, para ilustrar matérias, para servir de elementos pra vídeo, quer dizer, esse pessoal, muitas vezes, não recebe nada, não recebe nenhum benefício em troca. Chega o estrangeiro, como bonzinho, fotografa a baiana, que acordou muitas vezes 4 , 3 horas da manhã, pra ir pra feira de São Joaquim, comprar seu feijão pra fazer seu acarajé, chega um turista, pode ser até um cineasta, um fotógrafo profissional, que vai vender toda a beleza dessa mulher negra, no caso, dessa baiana que ele fotografou, no caso, a coitada, ele nem pede autorização pra fotografar. A gente percebe que essa cultura popular é bastante explorada. Outra coisa: os meios de comunicação de massa, as empresas de turismo, até 
as próprias empresas de aviação, quando querem trazer turistas, eles gostam muito de utilizar essa cultura popular, botar essa negra baiana sorridente bonita vendendo, essa tia Anastácia. Mas, no entanto, as filhas dessa baiana, ou dessas baianas, os seus filhos, que geralmente são rapazes pobres, saindo nos blocos afro, que também estão contribuindo de alguma forma com essa riqueza que é a cultura popular, essas pessoas, digamos, nunca são valorizadas. Os jornais, as revistas, o cinema, não têm nenhum pudor em tirar fotografia da baiana, de fotografar o pretinho vendendo picolé, mas só que ninguém quer dar emprego a esse pretinho de contínuo, ou quando esse pretinho ficar maior, pra trabalhar em um banco, em uma loja elegante, porque essas pessoas não têm boa aparência burgueses, dentro dos padrões de beleza limitados que impera em nossa sociedade.

$[\ldots]$.

Temos que atentar a essa questão muito séria sobre violência policial e cultura popular. Sou jornalista e sou baiano, sobretudo gosto muito dessa cultura popular, sabe? Eu sou uma pessoa que frequento ensaio de bloco afro, Ilê Aiyê, Muzenza e outros blocos mais que tem aqui em Salvador. Então, o que ocorre, é muito comum, sabe, tenho amigos nesses blocos, quando o menino vem do ensaio, já dançou seu ijexá, dele, muitas vezes o fotógrafo de um jornal, o cineasta já foi lá e fotografou: olha, que negro bonito, como ele dança bem. Mas muitas vezes, quando esse negro está vindo de seu ensaio do bloco, ele é abordado pela polícia, que o agride violentamente, quer dizer. Então, a gente questiona, dói muito perceber essa realidade, um pessoal que produz tanta coisa bonita pra esse Estado, pra essa Bahia, um pessoal que ajuda, traz dinheiro, a comunidade negra traz dinheiro pra esse Estado (VIEIRA, 1987).

O longo trecho justifica a citação. Hamilton já havia denunciado as estratégias de exploração, de baixa remuneração, de exclusão e de abuso das imagens dos sujeitos negros por parte do turismo, em matéria do jornal Nêgo (VIEIRA, 1984). Agora, ele vinha a público, em entrevista veiculada numa rádio com considerável audiência, fazer essa denúncia, a qual respingava nas tradições fotográficas que se construíram desde o século XIX, nos espaços discursivos da Antropologia e dos estúdios comerciais, e, mais recentemente, no cinema, no turismo e na publicidade - justamente alguns dos espaços mapeados por Fotobahia e para os quais se requeria a garantia adequada dos direitos autorais do fotógrafo. Hamilton apontava, por seu turno, para outra construção jurídica, que era o direito de imagem do fotografado, que só viria a ser mais explicitamente tematizado na Nova República e na crítica ao olhar de alteridade, no começo do século XXI.

Se, como pontuamos, essa era uma questão menor, entre as questões gravíssimas contra as quais se esbatia o protesto negro, ela não estava isenta do racismo. E resta que Hamilton Vieira aprofundava a crítica da visualidade no interior dos movimentos negros, e o 
fazia, não à toa, em interlocução com alguém que se entendeu fotógrafo na prática, por ver na imagem fotográfica um dispositivo de testemunho, de memória e de soberania do olhar negro sobre suas ações coletivas. O próprio Jônatas entendeu a dimensão visual da ação política coletiva ao fotografar a Marcha contra a Farsa da Abolição, em 12 de maio de 1988, quando os manifestantes queimaram na Praça Municipal um painel da Princesa Isabel e em seu lugar puseram um painel de Zumbi ${ }^{5}$.

Três anos depois da entrevista citada, foi criado o Zumvi Arquivo Fotográfico, por iniciativa dos fotógrafos Lázaro Roberto, Ademar Marques e Raimundo Monteiro, como uma agência de fotografia voltada para a cobertura das ações dos movimentos sociais da periferia de Salvador. Com o tempo, o Zumvi recebeu material produzido por sete fotógrafos ligados aos movimentos negros, incluindo o próprio Lázaro e Jônatas Conceição, seu amigo pessoal. Desse modo, mais de vinte anos depois do início de sua produção, a fotografia de Jônatas passou por um processo de arquivamento que a inseriu num ecossistema próprio, distinto do espaço privativo doméstico e aberto aos usos contemporâneos, como as intervenções de conservação, as novas exposições, a pesquisa, a edição de fotolivros e a circulação na internet.

No âmbito desse arquivo é que se tem compreendido que a indicada dimensão visual, cuja crítica Hamilton Vieira fez, já vinha sendo compreendida, pedagógica e culturalmente, desde que o MNU conferiu um uso social para as fotografias de Jônatas, ainda no período de sua feitura. Algumas poucas foram usadas em matérias do jornal Nêgo, enquanto outras, com cópias em papel, demonstram marcas materiais de terem sido expostas, além daquelas fotos que mostram exposições em espaços comunitários, em ambientes de organização, formação e deliberação política. A "Cidade Baixa", espaço periférico onde os grupos racializados e subalternizados redefiniram seu vínculo de raça e classe, criou seus próprios olhares, sem desconectar práticas culturais de processos econômico-sociais.

\section{Palavras finais: direito à imagem, direito à memória}

O que esse breve lampejo sobre as trajetórias desses fotógrafos negros nos sinaliza? O surgimento e a afirmação de profissionais negros na prática multifacetada da fotografia são recentes, datam das últimas décadas do século XX. Até os anos 1970, era raro o acesso de pessoas negras à prática fotográfica, não obstante o reconhecido contingente demográfico

\footnotetext{
${ }^{5}$ Em escala nacional, o trabalho de artistas visuais como Togo Iorubá, curadores como Emanoel Araújo e de críticos da publicidade e das imagens, como Edson Cardoso e Nelson Fernando Inocêncio da Silva também pontuavam criticamente a importância da visualidade.
} 
negro na Bahia e de tantas práticas, sonoridades, objetos e memórias relacionados a essa população ou por ela elaborados.

Neste texto, não desmerecemos os projetos documentais e experimentais de tantos fotógrafos brancos sobre personagens e práticas culturais negras, projetos bem-sucedidos e existentes praticamente desde que existe a fotografia, e que estiveram na agenda de vários integrantes de Fotobahia. Mas, ecoando Hamilton Vieira, questionamos, nas diferentes circunstâncias, sobre como se deu a negociação da imagem, no gesto de sua feitura, e os destinos éticos de seus usos, das políticas de Estado ao turismo, do conhecimento antropológico à veiculação midiática, do direito de ver e ter acesso à informação ao direito de ser visto ou interferir na política de visibilidade sobre suas imagens.

O que cabe ao fotógrafo branco que se propõe a fotografar pessoas negras? Hoje, as respostas a essa pergunta tendem a se tornar cada vez menos simples para os sujeitos brancos que, longe de serem universais, também se podem marcar racialmente.

Frantz Fanon (2008), na abertura de Pele negra, máscaras brancas, apontara o caráter ridicularizante, infantilizador, desracionalizante das imagens das pessoas negras na publicidade, especialmente em contextos coloniais. Cotidianamente, imagens de pessoas negras em situação de dor, opróbio e desumanização até hoje nos interpelam e nos convidam a não ver, a declinar desse gesto automático que se tornou a visualização nos regimes escópicos contemporâneos.

Ou bem podemos disputar, na esfera pública, a participação de produtores negros de imagens, a memória e a agência sobre suas práticas sociais. E aqui, ao destacarmos a importância da autoria negra nas imagens fotográficas, não o fazemos em defesa de uma suposta identidade ou lugar de fala e de criação essencializado, que credenciaria às pessoas negras olharem para suas práticas culturais de uma maneira mais correta ou aceitável, ou preveria uma forma pré-estabelecida do que é ser negro, de como fotografa uma pessoa negra. Vilma Neres (2021) relaciona a diversidade desses olhares com seu protagonismo social, chamando-o de fotoescrevivências, e isso implica a produção de imagem da parte dos sujeitos negros também quando eles se revoltam, protestam e propõem, por meio do discurso e da imagem, a sua emancipação de condições sociais desumanizantes.

O olhar negro, conforme a expressão de Januário Garcia, define-se por relações sociais, aprendizados culturais, modos coletivos de produção de subjetividade, e, 
particularmente, vivências de opressão, o que, no caso das pessoas racializadas, passa pela experiência nem sempre sutil, frequentemente violenta, do racismo, da precária construção da cidadania e do acesso a emprego, renda, saúde e moradia, do lastro de dispositivos, que, no poder, na linguagem, na psiché e, neste caso, nas imagens, constitui o que entendemos como raça, de acordo com Achille Mbembe (2018, p. 27-79) - se lembrarmos bem, essas questões todas estavam de certo modo sintetizadas na reivindicação por uma cidadania negra nas imagens, da parte de Hamilton Vieira. A cidadania, o pleno exercício de seus direitos e deveres em sociedade, aliás, sempre foi um dos direitos sociais fundamentais vetados aos grupos sociais negros no Pós-Abolição. Como vimos, nas imagens, isso foi conquistado em diferentes frentes, com maior ou menor ênfase no aspecto agonístico dessa conquista.

De dentro do dispositivo da raça, constituído para demarcar relações de poder, não foi de pouca relevância os negros terem aprendido a empunhar câmeras, eleger seus temas para fotografar, estarem presentes nas circunstâncias, valorar seus produtos no mercado, desenvolver estratégias para se manter, arquivar suas imagens, tanto no nível nos acervos pessoais e familiares, quanto no nível dos arquivos coletivos institucionalizados, os quais, de maneiras diferentes, permitem revisitarmos seus olhares e trajetórias, arejando sua materialidade e desestabilizando narrativas assentadas. Essa desestabilização implica, ainda, uma revisão crítica da própria historiografia, que excluiu as práticas fotográficas e de arquivo dos integrantes do Zumvi Arquivo Fotográfico, ao narrar a história da fotografia na Bahia na segunda metade do século XX e início do século XXI (FALCON, 2006).

Hoje, as imagens do protesto negro ocuparam o que estamos chamando de "Cidade Alta", isto é, os espaços consagrados do circuito expositivo, como na mostra "Memórias de Resistências Negras", realizada pelo Zumvi Arquivo Fotográfico no MAFRO/UFBA, em janeiro de $2018^{6}$. Cumpre pensar, portanto, sobre outras possíveis narrativas, em que há poética e política nessas práticas e nesses artefatos fotográficos, e que mesmo os fotógrafos não profissionais têm em seu olhar uma espessura culturalmente informada.

\section{Referências}

BAIRROS, Luiza. Orfeu e Poder: uma perspectiva afro-americana sobre a política racial no Brasil. Afro-Ásia, [s.1.] n. 17, p. 173-186, 1996. Disponível em: https://periodicos.ufba.br/index.php/afroasia/article/view/20863. Acesso em: 20 abr. 2021.

6 Lázaro Roberto comenta sobre essa exposição no website do MAFRO/UFBA: http://www.mafro.ceao.ufba.br/fr/node/117. 
COSTA, Helouise. Da fotografia como arte à arte como fotografia: a experiência do Museu de Arte Contemporânea da USP na década de 1970. Anais do Museu Paulista: História e Cultura Material, São Paulo, v. 16, n. 2, p. 131-173, jul./dez. 2008. Disponível em: https://www.revistas.usp.br/anaismp/article/view/5495. Acesso em: 30 maio 2015.

DAMASCENO, Victoria; FERNANDES, Samuel. Sob críticas por viés racial, reconhecimento facial chega a 20 estados. Folha de S. Paulo, 09 jul. 2021. Disponível em: https://www1.folha.uol.com.br/cotidiano/2021/07/sob-criticas-por-vies-racialreconhecimento-facial-chega-a-20-estados.shtml. Acesso em: 19 out. 2021.

EDWARDS, Elizabeth. Fotografias: a forma material e o arquivo dinâmico. In: FLORES, Teresa Mendes; CORREA, Sílvio Marcus de Sousa; VASCONCELOS, Soraya (coord.). Imagens \& Arquivos. Fotografias e filmes. Lisboa: Instituto de Comunicação da Nova, 2021. p. 14-29 (Coleção ICNOVA).

FALCÃO, Cíntia. Lentes racistas. Rui Costa está transformando a Bahia em um laboratório de vigilância com reconhecimento facial. The Intercept Brasil. 20 set. 2021. Disponível em: https://theintercept.com/2021/09/20/rui-costa-esta-transformando-a-bahia-em-um-laboratoriode-vigilancia-com-reconhecimento-facial/. Acesso em: 19 out. 2021.

FALCÓN, Gustavo. Notas, nomes e fatos da fotografia baiana (1950-2006). In: ALVES, Aristides (coord.). A fotografia na Bahia (1839-2006). Salvador: Asa Foto, 2006.

FANON, Frantz. Pele negra, máscaras brancas. Salvador: EDUFBA, 2008.

GARCIA, Januário. Entrevista concedida a Marcelo Reis. Programa Vivendo em Casa, n. 15, Disponível em: https:/www.youtube.com/watch?v=VapNjT6GH1M. Acesso em: 22 jul. 2021.

GELEDÉS; CULTNE; REDE DE HISTORIADORES NEGROS. 1970-1980: Nacionalização do Dia da Consciência Negra no Brasil. Google Arts \& Culture, 2020. Disponível em: https://artsandculture.google.com/exhibit/1970-1980-nacionaliza\%C3\%A7\%C3\%A3o-do-diada-consci\%C3\%AAncia-negra-no-brasil/fQJi_r65N9QKLg?hl=pt-br. Acesso em: 20 nov. 2020 .

GRUPO DE FOTÓGRAFOS DA BAHIA. Jornal Fotobahia. Salvador: [s.e.], 1981.

HURSTON, Zora Neale. O que os editores brancos não publicarão. Tradução e apresentação Messias Basques. Ayé: Revista de Antropologia, n. 1, v. 1, p. 106-111, 2019. Disponível em: https://revistas.unilab.edu.br/index.php/Antropologia/article/view/288. Acesso em: 19 out. 2020 .

KRAUSS, Rosalind. Os espaços discursivos da fotografia. In: KRAUSS, Rosalind. O fotográfico. Barcelona: Gustavo Gili, 2010. p. 40-59.

MAUAD, Ana Maria. História e semiótica: sobre o conceito de intertextualidade na análise de 
fontes de memória. In: MAUAD, Ana Maria. Poses e flagrantes. Ensaios sobre história e fotografias. Rio de Janeiro: EDUFF, 2008. p. 49-56.

MBEMBE, Achille. Crítica da razão negra. São Paulo: n-1 Edições, 2018.

MENESES, Ulpiano T. Bezerra de. A fotografia como documento - Robert Capa e o miliciano abatido na Espanha: sugestões para um estudo histórico. Tempo, Rio de Janeiro, n. 14, 2002.

MITCHELL, William John Thomas. O que as imagens realmente querem? In: ALLOA, Emanuel (org.). Pensar a imagem. São Paulo: Alameda, 2015. p. 165-190.

NEGRO, Antonio Luigi. O cartão-postal no Brasil do início do século XX: suporte para o encontro entre imagem e ação. História, Ciências, Saúde - Manguinhos, Rio de Janeiro, v. 27, n. 3, jul./set. 2020, p. 967-982. Disponível em: https://www.scielo.br/j/hcsm/a/Ln9mcNZZt9wCGfDPNCbwkhP/?format=pdf\&lang=pt. Acesso em: 19 out. 2020

NERES, Vilma. A escrita com a luz das fotoescrevivências. Salvador: Ed. da Autora, 2021.

OLSZEWSKI FILHA, Sofia. A fotografia e o negro na cidade de Salvador. Salvador: Empresa Gráfica da Bahia, 1989.

PINHO, Osmundo. O mundo negro: hermenêutica da reafricanização em Salvador. Curitiba: Progressiva, 2010.

ROUILLÉ, André. A fotografia entre documento e arte contemporânea. São Paulo: Senac, 2009.

SANSONE, Livio. Estados Unidos e Brasil no Gantois. O poder e a origem transnacional dos Estudos Afro-brasileiros. Revista Brasileira de Ciências Sociais, 27, n. 79, jun. 2012. Disponível em: https://www.scielo.br/j/rbcsoc/a/SkX5LcH596pVRhNNpWg9RjN/. Acesso em: 19 out. 2021.

SANTHIAGO, Ricardo. História oral e as artes: percursos, possibilidades e desafios. História Oral, v. 16, n. 1, p. 155-187. jan./jun. 2013. Disponível em: https://revista.historiaoral.org.br/index.php/rho/article/view/278. Acesso em: 30 jun. 2013.

SILVA, Ana Célia da. Um mundo em uma foto. Conversas de Historiadoras, 7 jun. 2020. Disponível em: https://conversadehistoriadoras.com/2020/06/07/um-mundo-em-uma-foto/. Acesso em: 7 jun. 2020.

SOUSA, Jorge Pedro. Uma história crítica do fotojornalismo ocidental. Chapecó: Argos; Florianópolis: Letras Contemporâneas, 2004.

UNIÃO DOS FOTÓGRAFOS DE BRASÍLIA. Manifesto dos fotógrafos. Brasília, 1981. Datilografado. 
VIEIRA, Hamilton. Entrevista concedida a Jônatas Conceição. Salvador, Programa Afro Bahia, n. 10, 21 ago. 1987. Disponível em:

https:/www.mixcloud.com/plataformajonatas/programa-afro-bahia-programa-10-gravadoem-21081987-pela-radio-educadora-da-bahia-irdeb/.. Acesso em: 10 maio 2021.

VIEIRA, Hamilton. O negro e a indústria do turismo. Nêgo. Salvador, n. 6, jun. 1984. Disponível em: http://negritos.com.br. Acesso em: 19 out. 2021.

Autor convidado. 